\title{
A Generalized State Space Average Model for Parallel DC-to-DC Converters
}

\author{
Hasan Alrajhi \\ Umm Al-Qura University, Makkah, 21955, Saudi Arabia \\ *Corresponding Author: Hasan Alrajhi. Email: Hkrajhi@uqu.edu.sa \\ Received: 27 June 2021; Accepted: 28 July 2021
}

\begin{abstract}
The high potentiality of integrating renewable energies, such as photovoltaic, into a modern electrical microgrid system, using DC-to-DC converters, raises some issues associated with controller loop design and system stability. The generalized state space average model (GSSAM) concept was consequently introduced to design a DC-to-DC converter controller in order to evaluate DC-toDC converter performance and to conduct stability studies. This paper presents a GSSAM for parallel DC-to-DC converters, namely: buck, boost, and buck-boost converters. The rationale of this study is that modern electrical systems, such as DC networks, hybrid microgrids, and electric ships, are formed by parallel DC-toDC converters with separate DC input sources. Therefore, this paper proposes a GSSAM for any number of parallel DC-to-DC converters. The proposed GSSAM is validated and investigated in a time-domain simulation environment, namely a MATLAB/SIMULINK. The study compares the steady-state, transient, and oscillatory performance of the state-space average model with a fully detailed switching model.
\end{abstract}

Keywords: Parallel DC-to-DC converters; generalized state space average model; buck converters; boost converters; buck-boost converters

\section{Introduction}

Due to the revolutionary development of modern electrical systems such as electric vehicles, ships, and microgrids, DC-to-DC converters are widely used in industry [1-6]. Moreover, DC-to-DC converters have become the cornerstone for active power systems, especially in DC and hybrid microgrids [7-11]. The longterm study of a fully detailed DC-to-DC converter requires not just a great deal of time but also an expensive computer unit [12]. Therefore, the conventional concept of a state-space average model of a DC-to-DC converter is used to minimize the simulation time as well as to design the converter controllers.

A small signal model of a DC-to-DC converter based on state-space is commonly applied as the interested frequency range, which is around one decade below the converter switching frequency [13]. Referring to [12], the dominant oscillatory behavior cannot be captured for some topologies, such as a resonant converter or a converter with a high ripple current. As a result, the large signal model of a DC-to-DC converter is not represented due to the sole consideration of the DC component of the Fourier coefficient. Hence, in order to design a reliable controller and to conduct stability studies, it is necessary

This work is licensed under a Creative Commons Attribution 4.0 International License, which permits unrestricted use, distribution, and reproduction in any medium, provided the original work is properly cited. 
to develop a large signal DC-to-DC converter model, including time-dependent coefficients that capture the oscillatory behavior.

Because of the complexity of control design and a transient evaluation, DC-to-DC converter behavior should be represented via a set of equations [14]. A generalized state space average model (GSSAM), which is the efficient method that is proposed in [15], can be developed to represent the DC-to-DC converter's transient, steady-state and switching dynamics. The GSSAM mainly depends on timedependent coefficients for one cycle of a given switching periodic signal [16]. Therefore, the switching periodic signal can be approximated to an arbitrary accuracy with a Fourier series representation [17]. The method takes the converter power during a switching period cycle and expresses it in terms of a group of state and output variables to represent the state space model [13].

The GSSAM has been extensively studied in the literature for a variety of converter topologies. In [18], the authors studied four basic DC-to-DC converter topologies, namely: buck, boost, buck-boost, and Cuk converters. The study of a single phase inverter was conducted in [19], based on applying a GSSAM, while a dual active bridge DC-to-DC converter was evaluated in $[20,21]$. Because of the distinct merit of a GSSAM in regards to control design, stability analysis, and simulation, this approach has the capability to be applied to electric machines and poly-phase systems such as an AC machine [22] and a three-phase six and twelve pulse diode rectifier [23]. A GSSAM for multi-phase DC-to-DC converters was recently studied and proposed in [12].

Motivated by the potential features and flexibility of the GSSAM, this paper presents further insights and investigations into parallel DC-to-DC converter topologies, namely: buck, boost, and buck-boost. To the author's best knowledge, the GSSAM has not yet been applied in the literature to parallel DC-to-DC converters with a separate DC source.

The contributions of this paper are as follows:

- The proposal of a GSSAM for n-parallel buck, boost, and buck-boost converters with a separate DC source for each converter.

- A comparison of the steady-state, transient and switching dynamics of the proposed GSSAM model with a switching model.

The rationale for proposing a GSSAM for parallel DC-to-DC converters is that a modern system configuration, such as a DC microgrid, is formed via an n-parallel connection of DC-to-DC converters with a separate DC source, as can be seen in [24-26]. Fig. 1 presents the general structure of a DC microgrid with different types of DC sources. In a DC microgrid, it is essential to operate parallel DC-toDC converters in order to improve the system's flexibility and reliability as well as to diminish the converter power stress [27]. This paper proposes an expandable GSSAM for n-parallel DC-to-DC converters. Therefore, while each converter can have different DC voltage levels and duty cycles, the output DC voltage for each converter must be identical.

This paper is organized into six sections: Section 2 provides a brief overview of the averaging complex

exponential while Section 3 explains the modelling of DC-to-DC converters. Section 4 presents a GSSAM of DC-to-DC converters while Section 5 discusses the simulation results. The final section presents the conclusions from this work.

\section{Brief Overview of the Averaging Complex Exponential}

Any periodic function can be mathematically represented based on a summation of sine and cosine functions. The general representation formula is known as a Fourier series and is shown in (1). 


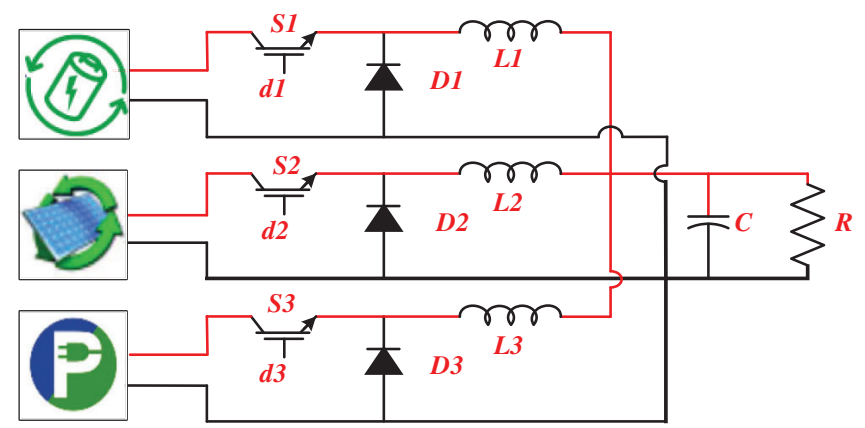

Figure 1: General structure of a DC microgrid

$f(t)=\frac{a_{o}}{2}+\sum_{n=1}^{\infty}\left[a_{n} \cos (n t)+b_{n} \sin (n t)\right]$

Most mathematical calculations become easier if an exponential function form is applied $\left(e^{\text {int }}\right)$ instead of using trigonometric functions. For simplicity, the general exponential representation of a Fourier series can be written in terms of the exponential function in (2):

$f(t)=\sum_{n=-\infty}^{\infty} F_{n} e^{i n t}$

where the $F_{n}$ coefficient is a constant real number when $n=0$, and is a complex number for all values of $n>0$, which appear in a conjugate pair. A conventional average state-space variable can be achieved by considering only one cycle of the switching signal [16], which is a DC component term that is given by (3):

$\langle f\rangle_{0}(t)=\frac{1}{T_{s}} \int_{t=T_{s}}^{t} f(t) . d t$

where $T_{S}$ is the switching period. Fig. 2 presents the waveform of the switching signal $u(t)$. The complex Fourier coefficients are given by (4) for the DC component and by (5) for the AC harmonics.

$$
\begin{aligned}
& C_{0}=\frac{1}{T_{s}} \int_{0}^{d T_{s}} u(t) d t=d \\
& C_{n}=\frac{1}{T_{s}} \int_{0}^{d T_{s}} u(t) e^{-i \omega n t} d t=\frac{1}{2 n \pi}\left(1-e^{-i \omega n t}\right)
\end{aligned}
$$

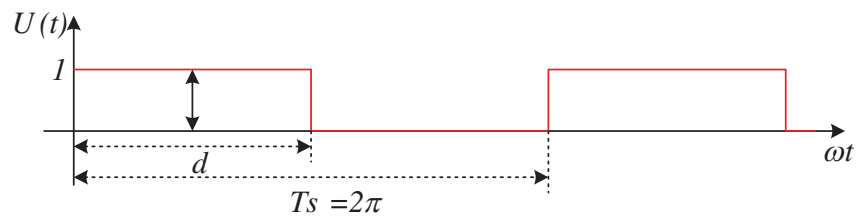

Figure 2: Switching signal waveform 
The switching frequency is donated via $\omega=2 \pi / T_{s}$. Rearranging and simplifying (5) allows the fundamental switching signal harmonic in terms of the sine function to be expressed as follows:

$C_{1}=\frac{\sin (\pi d)}{2 \pi}-j \frac{\sin ^{2}(\pi d)}{\pi}$

Therefore, the averaging AC harmonics of index-n can be determined by differentiation $f(t)$ with respect to time and computing the product of the switching signal $u(t)$ with the circuit state variable index-n, using the following formulas, respectively [16,18]:

$$
\begin{aligned}
& \frac{d\langle f\rangle_{n}(t)}{d t}=\left\langle\frac{d f}{d t}\right\rangle_{n}(t)-j n \omega\langle f\rangle_{n}(t) \\
& \langle u f\rangle_{n}=\sum_{i=-\infty}^{\infty}\langle u\rangle_{n-i}\langle f\rangle_{i}
\end{aligned}
$$

According to (8), the average product of index-n for signals can be calculated using a discrete convolution relationship, which leads to the following expressions for the DC component and the fundamental component, respectively [16]:

$$
\begin{aligned}
& \langle u f\rangle_{o}=\langle u\rangle_{o}\left\langle f_{o}\right\rangle+\langle u\rangle_{1}\langle f\rangle_{-1}+\langle u\rangle_{-1}\langle f\rangle_{1} \\
& \langle u f\rangle_{1}=\langle u\rangle_{o}\langle f\rangle_{1}+\langle u\rangle_{1}\langle f\rangle_{0}
\end{aligned}
$$

Eq. (9) gives the DC component of the state variable, which is referred to index-0. The complex state variables based on the fundamental component can be determined from (10). In (10), the conjugate component can be calculated by changing the index from a positive to a negative sign [16].

\section{Modelling of DC-to-DC Converters}

\subsection{Buck Converter Modelling}

The following generalized differential equations describe the voltage and current of n-parallel buck converters:

$$
\begin{aligned}
& \sum_{i=1}^{n} \frac{d i_{L i}}{d t}=\frac{V_{i n}^{i} u_{i}(t)}{L_{i}}-\frac{v_{c}}{L_{i}} \\
& \frac{d v c}{d t}=\sum_{i=1}^{n}\left(\frac{i L_{i}}{C}\right)-\frac{v_{c}}{R C}
\end{aligned}
$$

In this paper, a parallel buck switching model converter, which is shown in Fig. 3, is used for validation by comparing it with a state space average model. The differential equations of a large signal model can be found via applying both Kirchhoff's voltage and current laws. These laws should be applied during the twoswitch state. The state variable equations of the parallel buck converter are given in (13)-(15) while the switching function $u(t)$ is defined in (16).

$$
\begin{aligned}
& \frac{d i_{L 1}}{d t}=\frac{V_{i n 1} u_{1}(t)}{L_{1}}-\frac{v_{c}}{L_{1}} \\
& \frac{d i_{L 2}}{d t}=\frac{V_{i n 2} u_{2}(t)}{L_{2}}-\frac{v_{c}}{L_{2}}
\end{aligned}
$$


$\frac{d v c}{d t}=\frac{i L_{1}}{C}+\frac{i L_{2}}{C}-\frac{v_{c}}{R C}$

$u(t)=\left\{\begin{array}{lr}1, & 0<t<d T_{s} \\ 0, & d T_{s}<t<T_{s}\end{array}\right.$

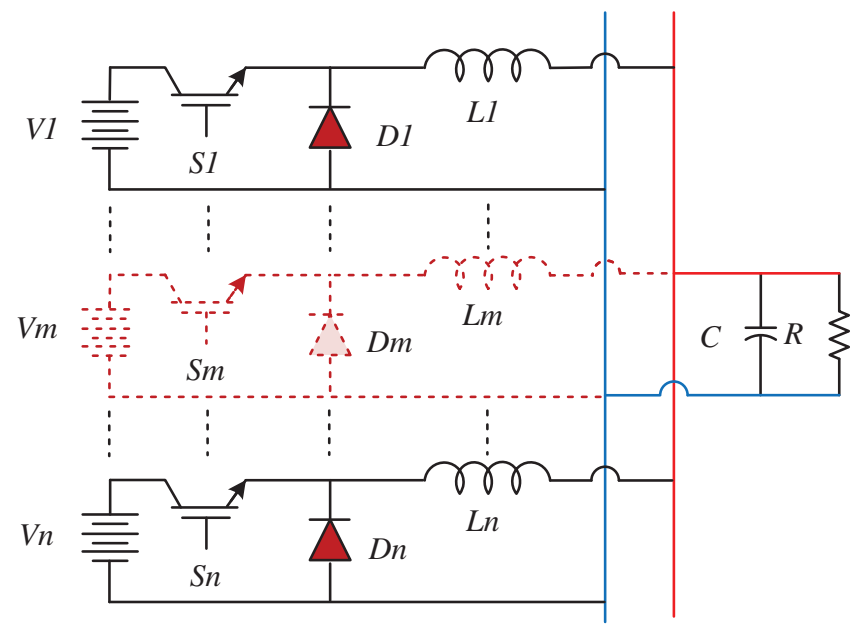

Figure 3: Parallel buck converters

Since circuit topology changes according to the switch mode of operation, the switching function determines the circuit topology over each switching cycle. The GSSAM of a buck converter mainly depends on the Fourier coefficients of state variables which, in this case, are $i L_{1}, i L_{2}$, and $v_{c}$. By including more terms of the Fourier series harmonics, it is possible to reduce any approximation error [15], but the use of higher order approximations increases the complexity of the model. Considering only the first-order approximation for a state-space model is beneficial for the sake of simplicity. Therefore, the first-order Fourier coefficient approximation of (13)-(15) can be written for the state variable as follows [18]:

$i_{L 1}=\left\langle i_{L 1}\right\rangle_{-1} e^{-i \omega t}+\left\langle i_{L 1}\right\rangle_{0}+\left\langle i_{L 1}\right\rangle_{1} e^{i \omega t}$

$i_{L 2}=\left\langle i_{L 2}\right\rangle_{-1} e^{-i \omega t}+\left\langle i_{L 2}\right\rangle_{0}+\left\langle i_{L 2}\right\rangle_{1} e^{i \omega t}$

$v_{c}=\left\langle v_{c}\right\rangle_{-1} e^{-i \omega t}+\left\langle v_{c}\right\rangle_{0}+\left\langle v_{c}\right\rangle_{1} e^{i \omega t}$

where $\left\langle i_{L 1}\right\rangle_{0},\left\langle i_{L 1}\right\rangle_{0}$, and $\left\langle v_{c}\right\rangle_{0}$ are the DC components of the Fourier coefficient while $\left\langle i_{L 1}\right\rangle_{1},\left\langle i_{L 1}\right\rangle_{1}$ and $\left\langle v_{c}\right\rangle_{1}$ are the complex first-order harmonic. The negative sign of the complex first-order harmonic indicates the complex conjugate quantity. For mathematical simplicity of driving the generalized state-space average model, the quantities in (17)-(19) can be expanded and written as follows:

$$
\begin{array}{lll}
\left\langle i_{L 1}\right\rangle_{0}=x_{1} & \left\langle i_{L 1}\right\rangle_{1}=x_{4}+j x_{5} & \left\langle i_{L 1}\right\rangle_{-1}=x_{4}-j x_{5} \\
\left\langle i_{L 2}\right\rangle_{0}=x_{2} & \left\langle i_{L 1}\right\rangle_{1}=x_{6}+j x_{7} & \left\langle i_{L 1}\right\rangle_{-1}=x_{6}-j x_{8} \\
\left\langle v_{c}\right\rangle_{0}=x_{3} & \left\langle i_{L 1}\right\rangle_{1}=x_{8}+j x_{9} & \left\langle i_{L 1}\right\rangle_{-1}=x_{7}-j x_{9}
\end{array}
$$


The differential equations that form the state-space average model can be found by applying (7) and (8) and substituting (4), (5), (20)-(22) into (13)-(15). Therefore, the differential equations of the state-space model of a parallel buck converter are:

$$
\begin{aligned}
\left\langle x_{1}\right\rangle_{0} & =\frac{V_{\text {in } 1}}{L_{1}} d_{1}-\frac{x_{3}}{L_{1}} \\
\left\langle x_{2}\right\rangle_{0} & =\frac{V_{i n 2}}{L_{2}} d_{2}-\frac{x_{3}}{L_{3}} \\
\left\langle x_{3}\right\rangle_{0} & =\frac{x_{1}}{C}+\frac{x_{2}}{C}-\frac{x_{3}}{R C} \\
\left\langle x_{4}\right\rangle_{1}^{\mathcal{R}} & =\frac{V_{\text {in } 1} \sin \left(2 \pi d_{1}\right)}{2 \pi L_{1}}-\frac{x_{8}}{L_{1}}+\omega x_{5} \\
\left\langle x_{5}\right\rangle_{1}^{I} & =-\frac{V_{\text {in } 1} \sin ^{2}\left(\pi d_{1}\right)}{\pi L_{1}}+\frac{x_{9}}{L_{1}}-\omega x_{4} \\
\left\langle x_{6}\right\rangle_{1}^{\mathcal{R}} & =\frac{V_{\text {in } 1} \sin \left(2 \pi d_{2}\right)}{2 \pi L_{2}}-\frac{x_{8}}{L_{2}}+\omega x_{7} \\
\left\langle x_{7}\right\rangle_{1}^{I} & =-\frac{V_{i n 1} \sin ^{2}\left(\pi d_{2}\right)}{\pi L_{2}}+\frac{x_{9}}{L_{2}}-\omega x_{6} \\
\left\langle x_{8}\right\rangle_{1}^{\mathcal{R}} & =\frac{x_{4}}{C}+\frac{x_{6}}{C}-\frac{x_{8}}{R C}+\omega x_{9} \\
\left\langle x_{9}\right\rangle_{1}^{I} & =\frac{x_{5}}{C}+\frac{x_{7}}{C}-\frac{x_{9}}{R C}-\omega x_{8}
\end{aligned}
$$

The circuit state variables of a parallel buck converter are calculated from (23)-(31) by applying the following equations:

$i_{L 1}=x_{1}+2 x_{4} \cos (\omega t)-j 2 x_{5} \sin (\omega t)$

$i_{L 2}=x_{2}+2 x_{6} \cos (\omega t)-j 2 x_{7} \sin (\omega t)$

$v_{c}=x_{3}+2 x_{8} \cos (\omega t)-j 2 x_{9} \sin (\omega t)$

\subsection{Boost Converter Modelling}

The following generalized differential equations describe the voltage and current of n-parallel boost converters:

$\sum_{i=1}^{n} \frac{d i_{L i}}{d t}=\frac{V_{i n}^{i}}{L_{i}}-\frac{u_{i}(t) v_{c}}{L_{i}}+\frac{v_{c}}{L_{i}}$

$\frac{d v c}{d t}=\sum_{i=1}^{n}\left(-\frac{i L_{i}}{C}\right)+\sum_{i=1}^{n}\left(\frac{u_{i}(t) i L_{i}}{C}\right)-\frac{v_{c}}{R C}$

An n-parallel boost switching model converter, which is shown in Fig. 4, is used for validation by comparing it with a state space average model. The large signal model of the two parallel boost converters can be described as: 


$$
\begin{aligned}
& \frac{d i_{L 1}}{d t}=\frac{V_{i n 1}}{L_{1}}-\frac{u_{1}(t) v_{c}}{L_{1}}+\frac{v_{c}}{L_{2}} \\
& \frac{d i_{L 2}}{d t}=\frac{V_{i n 2}}{L_{2}}-\frac{u_{2}(t) v_{c}}{L_{2}}+\frac{v_{c}}{L_{2}} \\
& \frac{d v c}{d t}=-\frac{i L_{1}}{C}-\frac{i L_{2}}{C}+\frac{u_{1}(t) i L_{1}}{C}+\frac{u_{2}(t) i L_{2}}{C}-\frac{v_{c}}{R C}
\end{aligned}
$$

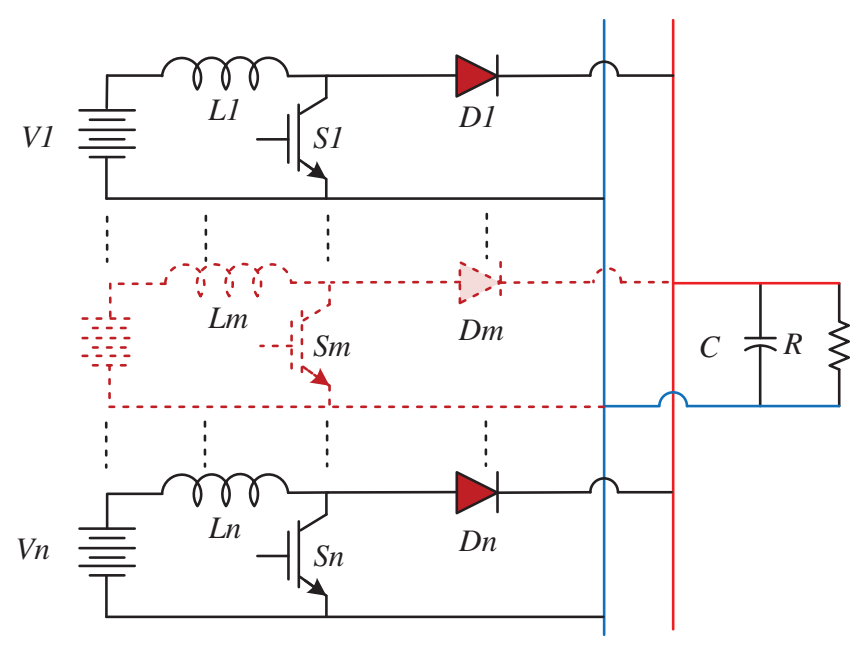

Figure 4: Parallel boost converters

In order to avoid repetition, the same procedure that is explained in Section 3.1 can be applied. Hence, the differential equations of a parallel boost converter, as described in (40)-(48), are as follows:

$$
\begin{aligned}
& \left\langle x_{1}\right\rangle_{0}=\frac{V_{i n 1}}{L_{1}}-\frac{\left(1-d_{1}\right)}{L_{1}} x_{3}-\frac{2 \sin \left(2 \pi d_{1}\right)}{2 \pi L_{1}} x_{8}+\frac{2 \sin ^{2}\left(\pi d_{1}\right)}{\pi L_{1}} x_{9} \\
& \left\langle x_{2}\right\rangle_{0}=\frac{V_{i n 2}}{L_{2}}-\frac{\left(1-d_{2}\right)}{L_{2}} x_{3}-\frac{2 \sin \left(2 \pi d_{2}\right)}{2 \pi L_{2}} x_{8}+\frac{2 \sin ^{2}\left(\pi d_{2}\right)}{\pi L_{2}} x_{9} \\
& \left\langle x_{3}\right\rangle_{0}=\frac{\left(d_{1}-1\right)}{C} x_{1}+\frac{\left(d_{2}-1\right)}{C} x_{2}-\frac{x_{3}}{R C}-\frac{2 \sin \left(2 \pi d_{1}\right)}{2 \pi L_{1}} x_{4}+\frac{2 \sin ^{2}\left(\pi d_{1}\right)}{\pi L_{1}} x_{5}-\frac{2 \sin \left(2 \pi d_{2}\right)}{2 \pi L_{2}} x_{6}+\frac{2 \sin ^{2}\left(\pi d_{2}\right)}{\pi L_{2}} x_{7} \\
& \left\langle x_{4}\right\rangle_{1}^{\mathcal{R}}=\frac{V_{\text {in } 1}}{L_{1}}+\frac{\sin \left(2 \pi d_{1}\right)}{2 \pi L_{1}} x_{3}+\frac{\left(1-d_{1}\right)}{L_{1}} x_{8}+\omega x_{5} \\
& \left\langle x_{5}\right\rangle_{1}^{I}=\frac{\sin ^{2}\left(\pi d_{1}\right)}{\pi L_{1}} x_{3}-\omega x_{4}+\frac{\left(1-d_{1}\right)}{L_{1}} x_{9} \\
& \left\langle x_{6}\right\rangle_{1}^{\mathcal{R}}=\frac{V_{\text {in } 2}}{L_{2}}+\frac{\sin \left(2 \pi d_{2}\right)}{2 \pi L_{2}} x_{3}+\frac{\left(1-d_{2}\right)}{L_{2}} x_{8}+\omega x_{5}
\end{aligned}
$$




$$
\begin{aligned}
& \left\langle x_{7}\right\rangle_{1}^{I}=\frac{\sin ^{2}\left(\pi d_{2}\right)}{\pi L_{2}} x_{3}-\omega x_{4}+\frac{\left(1-d_{2}\right)}{L_{2}} x_{9} \\
& \left\langle x_{8}\right\rangle_{1}^{\mathcal{R}}=\frac{\sin \left(2 \pi d_{1}\right)}{2 \pi C} x_{1}+\frac{\sin \left(2 \pi d_{2}\right)}{2 \pi C} x_{2}+\frac{\left(d_{1}-1\right)}{L_{1}} x_{4}+\frac{\left(d_{2}-1\right)}{L_{1}} x_{6}-\frac{x_{8}}{R C}+\omega x_{9} \\
& \left\langle x_{9}\right\rangle_{1}^{I}=-\frac{\sin ^{2}\left(\pi d_{1}\right)}{2 \pi C} x_{1}-\frac{\sin ^{2}\left(\pi d_{2}\right)}{2 \pi C} x_{2}+\frac{\left(d_{1}-1\right)}{L_{1}} x_{5}+\frac{\left(d_{2}-1\right)}{L_{1}} x_{7}+\omega x_{8}-\frac{x_{9}}{R C}
\end{aligned}
$$

The circuit state variables of a parallel boost converter are calculated according to (20)-(22).

\subsection{Buck-Boost Converter Modelling}

The following generalized differential equations describe the voltage and current of n-parallel buckboost converters:

$\sum_{i=1}^{n} \frac{d i_{L i}}{d t}=\frac{V_{i n}^{i} u_{i}(t)}{L_{i}}-\frac{u_{i}(t) v_{c}}{L_{i}}+\frac{v_{c}}{L_{i}}$
$\frac{d v c}{d t}=\sum_{i=1}^{n}\left(-\frac{i L_{i}}{C}\right)+\sum_{i=1}^{n}\left(\frac{u_{i}(t) i L_{i}}{C}\right)-\frac{v_{c}}{R C}$

An n-parallel buck-boost switching model converter, which is shown in Fig. 5, is used for validation by comparing it with a state space average model. The differential equations of a large parallel buck-boost converter signal model, based on the state variables, are given as:

$$
\begin{aligned}
& \frac{d i_{L 1}}{d t}=\frac{V_{i n 1} u_{1}(t)}{L_{1}}-\frac{u_{1}(t) v_{c}}{L_{1}}+\frac{v_{c}}{L_{1}} \\
& \frac{d i_{L 2}}{d t}=\frac{V_{i n 1} u_{2}(t)}{L_{2}}-\frac{u_{2}(t) v_{c}}{L_{2}}+\frac{v_{c}}{L_{2}} \\
& \frac{d v c}{d t}=-\frac{i L_{1}}{C}-\frac{i L_{2}}{C}+\frac{u_{1}(t) i L_{1}}{C}+\frac{u_{2}(t) i L_{2}}{C}-\frac{v_{c}}{R C}
\end{aligned}
$$

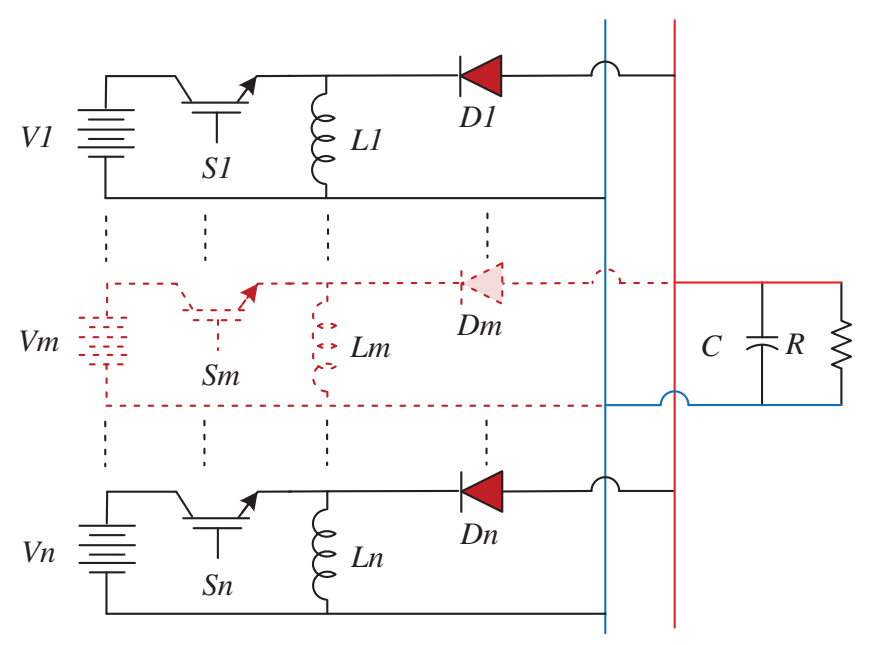

Figure 5: Parallel buck-boost converters 
The state variables of buck-boost converters are similar to boost converters. Therefore, the differential equations that form state space representation, based on the multi-frequency averaging model, are found as follows:

$$
\begin{aligned}
& \left\langle x_{1}\right\rangle_{0}=\frac{d_{1} V_{i n 1}}{L_{1}}+\frac{\left(d_{1}-1\right)}{L_{1}} x_{3}+\frac{2 \sin \left(2 \pi d_{1}\right)}{2 \pi L_{1}} x_{8}-\frac{2 \sin ^{2}\left(\pi d_{1}\right)}{\pi L_{1}} x_{9} \\
& \left\langle x_{2}\right\rangle_{0}=\frac{d_{2} V_{i n 2}}{L_{2}}+\frac{\left(d_{2}-1\right)}{L_{2}} x_{3}+\frac{2 \sin \left(2 \pi d_{2}\right)}{2 \pi L_{2}} x_{8}-\frac{2 \sin ^{2}\left(\pi d_{2}\right)}{\pi L_{2}} x_{9} \\
& \left\langle x_{3}\right\rangle_{0}=\frac{\left(1-d_{1}\right)}{C} x_{1}+\frac{\left(1-d_{2}\right)}{C} x_{2}-\frac{x_{3}}{R C}-\frac{2 \sin \left(2 \pi d_{1}\right)}{2 \pi L_{1}} x_{4}+\frac{2 \sin ^{2}\left(\pi d_{1}\right)}{\pi L_{1}} x_{5}-\frac{2 \sin \left(2 \pi d_{2}\right)}{2 \pi L_{2}} x_{6}+\frac{2 \sin ^{2}\left(\pi d_{2}\right)}{\pi L_{2}} x_{7} \\
& \left\langle x_{4}\right\rangle_{1}^{\mathcal{R}}=\frac{d_{1} V_{i n 1}}{L_{1}}+\frac{\sin \left(2 \pi d_{1}\right)}{2 \pi L_{1}} x_{3}+\frac{\left(d_{1}-1\right)}{L_{1}} x_{8}+\omega x_{5} \\
& \left\langle x_{5}\right\rangle_{1}^{I}=-\frac{\sin ^{2}\left(\pi d_{1}\right)}{\pi L_{1}} x_{3}-\omega x_{4}+\frac{\left(d_{1}-1\right)}{L_{1}} x_{9} \\
& \left\langle x_{6}\right\rangle_{1}^{\mathcal{R}}=\frac{d_{2} V_{i n 2}}{L_{2}}+\frac{\sin \left(2 \pi d_{2}\right)}{2 \pi L_{2}} x_{3}+\frac{\left(d_{2}-1\right)}{L_{2}} x_{8}+\omega x_{7} \\
& \left\langle x_{7}\right\rangle_{1}^{I}=-\frac{\sin ^{2}\left(\pi d_{2}\right)}{\pi L_{2}} x_{3}-\omega x_{6}+\frac{\left(d_{2}-1\right)}{L_{2}} x_{9} \\
& \left\langle x_{8}\right\rangle_{1}^{\mathcal{R}}=-\frac{\sin ^{2}\left(2 \pi d_{1}\right)}{2 \pi C} x_{1}-\frac{\sin \left(2 \pi d_{2}\right)}{2 \pi C} x_{2}+\frac{\left(1-d_{1}\right)}{L_{1}} x_{4}+\frac{\left(1-d_{2}\right)}{L_{1}} x_{6}-\frac{x_{8}}{R C}+\omega x_{9} \\
& \left\langle x_{9}\right\rangle_{1}^{I}=-\frac{\sin ^{2}\left(\pi d_{1}\right)}{2 \pi C} x_{1}-\frac{\sin ^{2}\left(\pi d_{2}\right)}{2 \pi C} x_{2}+\frac{\left(1-d_{1}\right)}{L_{1}} x_{5}+\frac{\left(1-d_{2}\right)}{L_{1}} x_{7}+\omega x_{8}-\frac{x_{9}}{R C}
\end{aligned}
$$

Based on the previous equation, the circuit state variables of a parallel buck-boost converter are determined using (20)-(22).

\section{Generalized State-Space Average Model of DC-to-DC Converters}

This section presents the GSSAM of a DC-to-DC converter based on matrix representation, which is a beneficial representation for controller design. The GSSAMs of the n-parallel buck, boost, and buck-boost converters are illustrated in (63)-(65), respectively. The GSSAM of two parallel buck converters is illustrated in (63):

$$
\left[x_{\text {buck }}\right]=\left[A_{\text {sys }}^{\text {buck }}\right]_{(3 n+3) \times(3 n+3)}\left[x_{\text {buck }}\right]+\left[B_{\text {input }}^{\text {buck }}\right]\left[\begin{array}{c}
V_{\text {in } 1} \\
V_{\text {in } 2}
\end{array}\right]_{1 \times n}^{T}
$$

where $\mathrm{n}$ in the subscript indicates the number of parallel converters, and $A_{s y s}^{b u c k}$ is the system matrix, which is given in Appendix (A.2). Hence, the expanded states and input matrixes are shown as follows:

$$
\left[x_{\text {buck }}\right]=\left[x_{1}^{0}, x_{2}^{0} \cdots x_{3}^{0}, x_{1}^{R}, x_{1}^{I}, x_{2}^{\mathcal{R}}, \cdots x_{3}^{R}, x_{3}^{I}\right]^{T}
$$




$$
\left[B_{\text {input }}^{\text {Buck }}\right]=\left[\frac{d_{1}}{L_{1}}, \frac{d_{2}}{L_{2}} \cdots 0, \frac{d_{1}}{L_{1}}, 0, \frac{d_{2}}{L_{2}}, 0, \ldots 0,0\right]^{T}
$$

The GSSAM of two parallel boost converters is illustrated in (66):

$$
\left[x_{\text {boost }}\right]=\left[A_{\text {sys }}^{\text {boost }}\right]_{(3 n+3) \times(3 n+3)}\left[x_{\text {boost }}\right]+\left[B_{\text {input }}^{\text {boos }}\right]\left[\begin{array}{c}
V_{\text {in } 1} \\
V_{\text {in } 2}
\end{array}\right]_{1 \times n}^{T}
$$

where the expanded states and input matrixes of the boost converter are given below, and the system matrix $A_{\text {sys }}^{\text {boost }}$ is given in Appendix (A.3).

$$
\begin{aligned}
& {\left[x_{\text {boost }}\right]=\left[x_{1}^{0}, x_{2}^{0} \cdots x_{3}^{0}, x_{1}^{R}, x_{1}^{I}, x_{2}^{\mathcal{R}}, \cdots x_{3}^{R}, x_{3}^{I}\right]^{T}} \\
& {\left[B_{\text {input }}^{\text {boost }}\right]=\left[\frac{d_{1}}{L_{1}}, \frac{d_{2}}{L_{2}} \cdots \quad 0 \quad \sin \frac{\left(2 \pi d_{1}\right)}{2 \pi L_{1}}, \quad-\sin ^{2} \frac{\left(\pi d_{1}\right)}{\pi L_{1}}, \quad \sin \frac{\left(2 \pi d_{2}\right)}{2 \pi L_{2}}, \quad-\sin ^{2} \frac{\left(\pi d_{2}\right)}{\pi L_{2}}, \cdots 0,0\right]^{T}}
\end{aligned}
$$

The GSSAM of two parallel buck-boost converters is illustrated in (69):

$$
\left[x_{\text {buck-boost }}\right]=\left[A_{\text {sys }}^{\text {buck-boost }}\right]_{(3 n+3) \times(3 n+3)}\left[x_{\text {buck-boost }}\right]+\left[B_{\text {input }}^{\text {buck-boost }}\right]\left[\begin{array}{c}
V_{\text {in } 1} \\
V_{\text {in } 2}
\end{array}\right]_{1 \times n}^{T}
$$

were the expanded states and input matrixes of the buck-boost converter are identical to (67) and (68), while $A_{\text {sys }}^{\text {buck-boost }}$ is given in Appendix (A.4).

The previous Eqs. (63)-(65) can be expanded for n-number of parallel DC-to-DC converters, namely by replacing only three-dots (:) in the matrices with the current state differential equations in the system state matrix as well as in the input matrix. Furthermore, considering more Fourier harmonics will increase the system and the input matrix order. Hence, the accuracy of the GSSAM will be improved.

\section{Simulation Results and Discussion}

The GSSAM of parallel DC-to-DC converters is conducted in a MATLAB/SIMULINK environment, which is compared with a detailed switching model.

\subsection{Buck Converter Behavior}

Fig. 6 presents the electrical quantities of the two parallel DC-to-DC buck converters, namely the inductor currents and capacitor voltage. The inductor currents of the parallel buck converters are depicted in Figs. 6a and 6b, respectively while the capacitor voltage is shown in Fig. 6c. The total load current is the summation of both inductor currents, which is presented in Fig. 6d.

The zero-order model is mainly based on the DC component of the Fourier series, which corresponds to (4), as depicted in Fig. 6 in the gray color. The moving average complex states, including the DC component of the currents and the voltage, are referred to (6) and (8). The results show that there is no significant difference between the state-space average models and the fully switched detailed model. In fact, the dynamic and oscillatory behavior of the average state-space models can be captured. Therefore, including more harmonic coefficients of the Fourier series leads to an increase in the model order, which improves the model accuracy and increases the model complexity. 


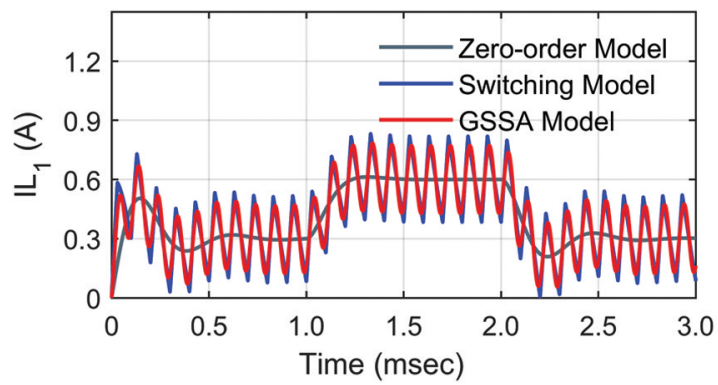

(a)

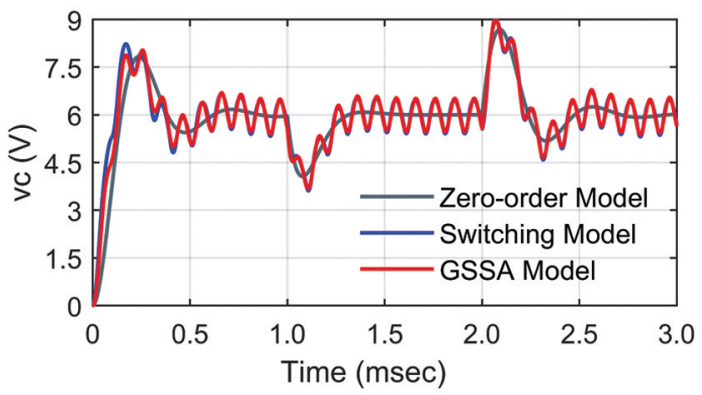

(c)

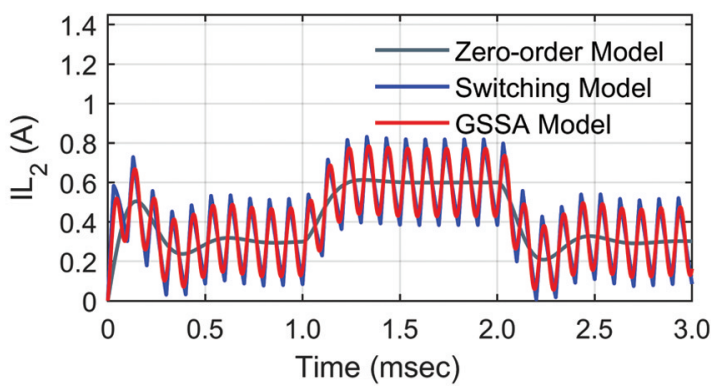

(b)

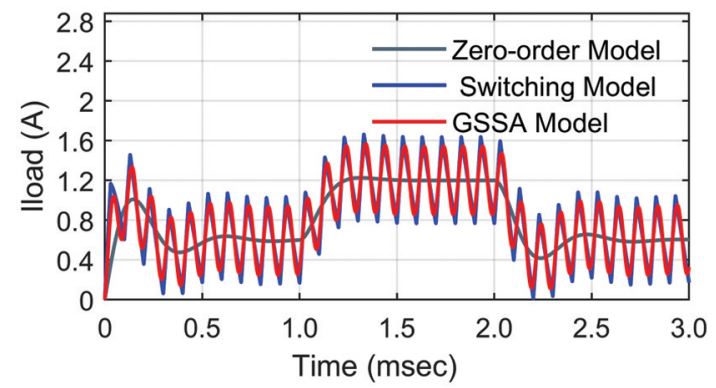

(d)

Figure 6: Parallel buck converter currents and output voltage. (a) Converter \#1 inductor current, (b) Converter \#2 inductor current, (c) Output voltage, (d) Load current

In this case, the DC load voltage is assumed to be fixed due to a constant duty cycle. Initially, at $\mathrm{t}=0 \mathrm{~s}$, the converters start to supply the DC load according to its resistance which, in this case, is equal to $10 \Omega$. At $\mathrm{t}=1 \mathrm{~ms}$, the DC load changes to be equal to $5 \Omega$, therefore the load becomes double and both converters equally share the load current. The transient response of the proposed model is obviously seen to be identical to the switched model. At $\mathrm{t}=2 \mathrm{~ms}$, the DC load is reduced to be equal to $10 \Omega$. During the load step change, the DC voltage remains at the same level except during the load transition, which has regular transient response. It is noted that the proposed GSSAM of the parallel buck converter presents the transient, steady state, and switching dynamic of the converters, based on the operation conditions.

\subsection{Boost Converter Behavior}

The electrical quantities of the parallel DC-to-DC boost converter are presented in Fig. 7. These quantities are the inductor current and capacitor voltage. Figs. $7 \mathrm{a}$ and $7 \mathrm{~b}$, respectively, present the inductor currents of the two parallel boost converters. In this converter topology, it can be seen that there is a coupling term in the state variable equations, which raises the converter model complexity [18]. In other words, the state variables are multiplied by the duty cycle signal, therefore the GSSAM is just approximated by considering only the zero- and first-order of Fourier series harmonics [12]. The GSSAM based on zero- and first-order harmonics still captures the converter' current and voltage behaviors. Hence, the capacitor voltage of the parallel DC-to-DC boost converter is shown in Fig. 7c while the total load current is presented in Fig. 6d. Since the output DC voltage of the boost converter is based on the input voltage divided by $(1-d)$, this relationship increases the complexity of the boost converter.

Initially, at $\mathrm{t}=0 \mathrm{~s}$, both the GSSAM and switching models start to feed the connected DC load according to the applied duty cycle which is, in this case, equal to 0.25 . It can be clearly observed that both boost converters have an identical response. A double increase of the DC load step change takes place at $\mathrm{t}=1 \mathrm{~ms}$. Therefore, both converter currents are increased accordingly and the DC voltage for both the 
GSSAM and switching models have an identical transient response, as shown in Fig. 7c. The DC load is reduced by half at $\mathrm{t}=2 \mathrm{~ms}$, so the transient response of both converters matches the switching converter model.

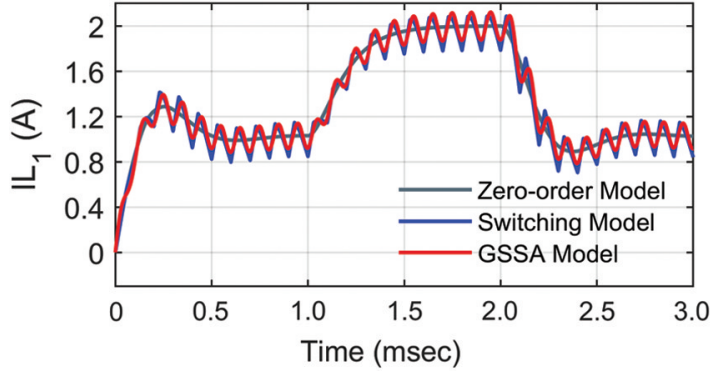

(a)

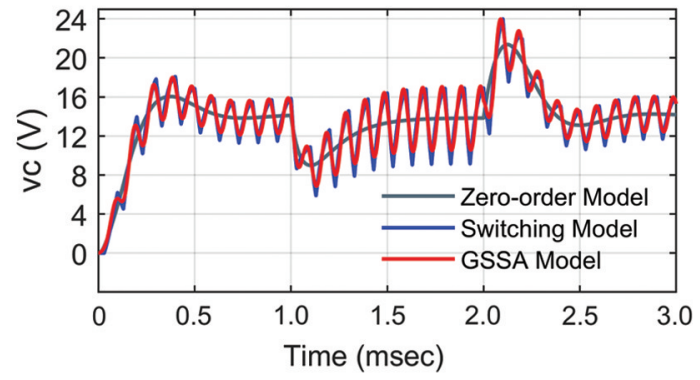

(c)

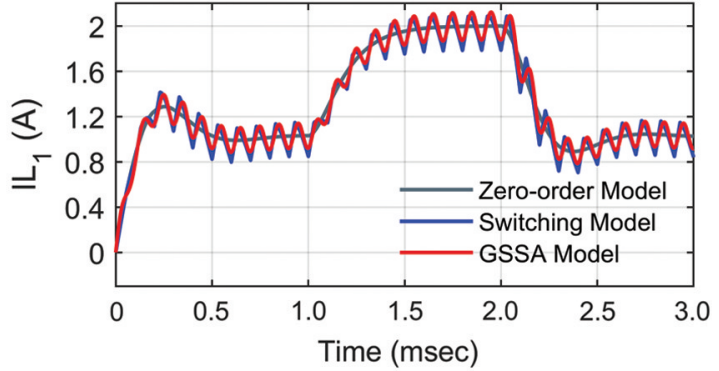

(b)

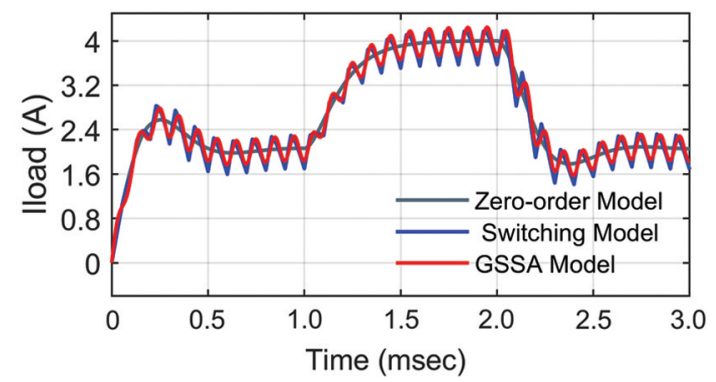

(d)

Figure 7: Parallel boost converter currents and output voltage at $d=0.25$. (a) Converter $\# 1$ inductor current, (b) Converter \#2 inductor current, (c) Output voltage, (d) Load current

Fig. 8 presents the model difference between the GSSAM and the fully detailed switching model when the duty cycle is equal to 0.7 . It can be clearly seen that, for both parallel boost converters, the inductor current shows some error difference compared to the switching model, as illustrated in Figs. 8a and 8b, respectively. Hence, the inductor currents will affect the total load current, as shown in Fig. 8d. The output DC voltage is less affected than the inductor currents due to an increase in duty cycle, as depicted in Fig. 8c. The GSSAM of the boost converter shows some differences compared to the switching model once the duty cycle is increased. The reason behind this issue is that the switching frequency should be selected to be higher than a converter's RLC natural frequency in order to eliminate the high order harmonics [12]. Therefore, this converter topology requires proper choice of switching frequency or inclusion of more Fourier harmonics in order to achieve accurate performance of the average model when the duty cycle becomes more than 0.5 due to the existence of even harmonics [13].

\subsection{Buck-Boost Converter Behavior}

Fig. 9 shows the parallel DC-to-DC buck-boost converter inductor current and capacitor voltage. In Figs. 9a and 9b, respectively, the currents of the parallel buck-boost converters are depicted while the capacitor voltage is shown in Fig. 9c. The summation of both inductor currents gives the total load current, as presented in Fig. 9d. 


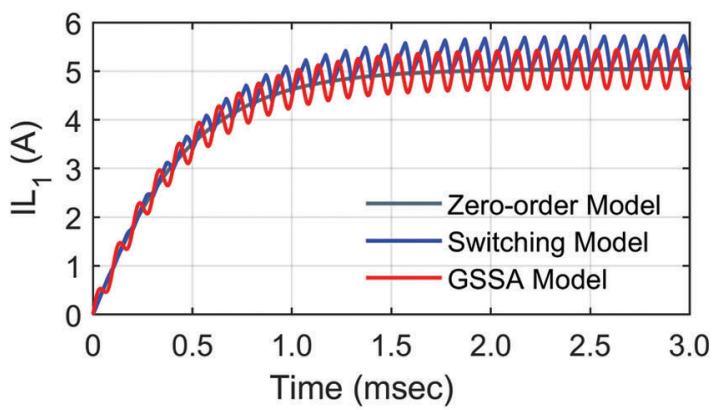

(a)

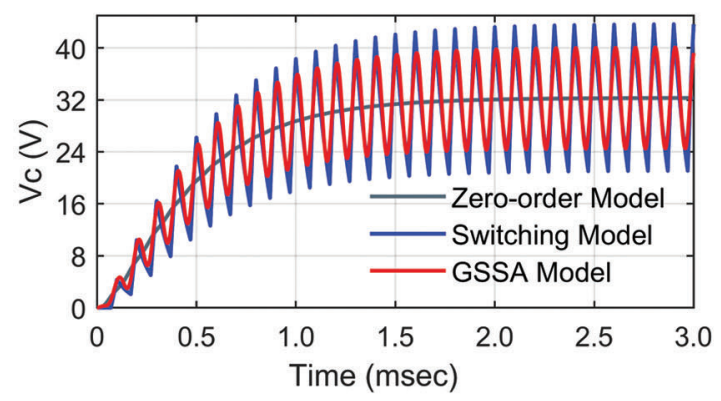

(c)

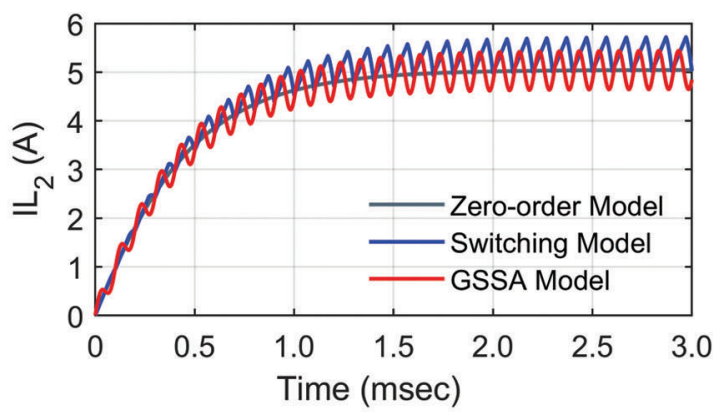

(b)

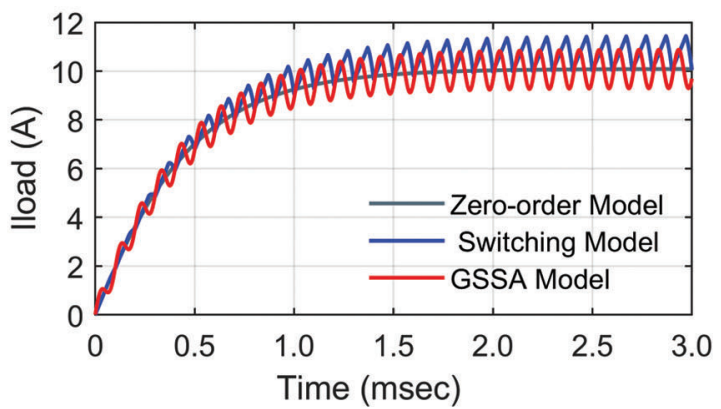

(d)

Figure 8: Parallel boost converter currents and output voltage at $d=0.7$. (a) Converter \#1 inductor current, (b) Converter \#2 inductor current, (c) Output voltage, (d) Load current

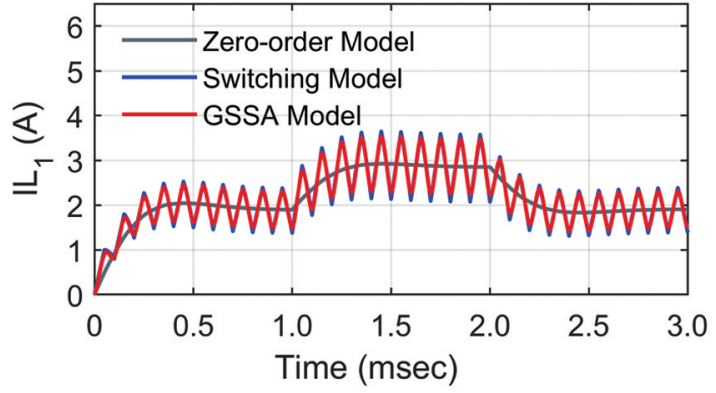

(a)

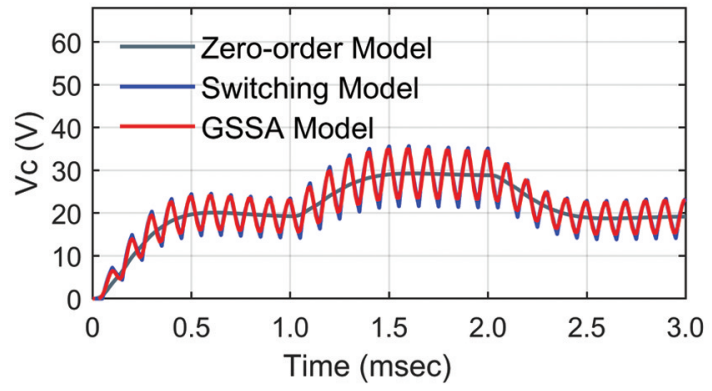

(c)

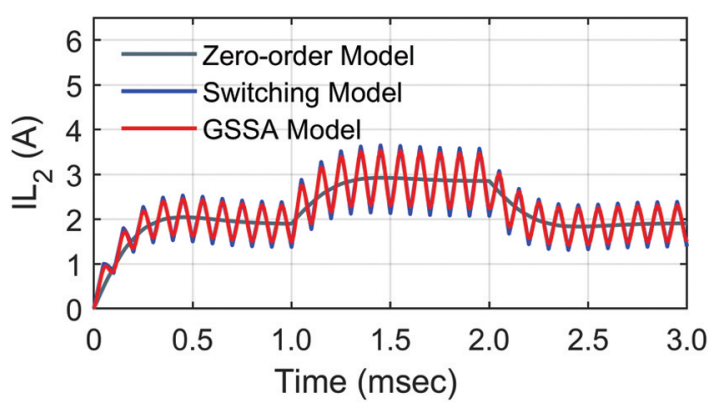

(b)

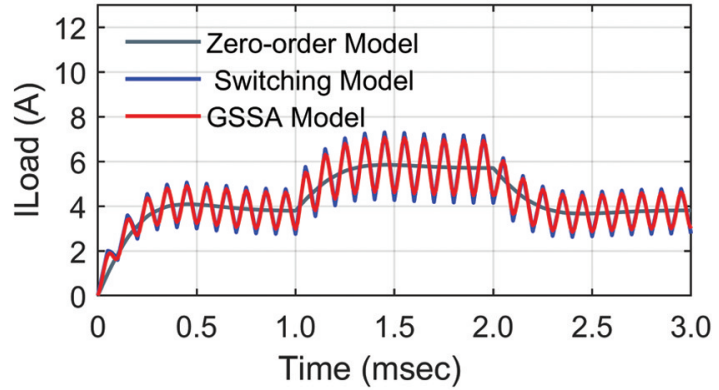

(d)

Figure 9: Parallel buck-boost converter currents and output voltage at $d=0.3$. (a) Converter \#1 inductor current, (b) Converter \#2 inductor current, (c) Output voltage, (d) Load current 
This case evaluates parallel buck-boost converters during a step change of input voltages. During the interval $\mathrm{t}=0$ to $\mathrm{t}=1 \mathrm{~ms}$, both converters are fed via a DC voltage equal to $20 \mathrm{~V}$ and duty cycles equal to 0.5 . The GSSAM captures the dynamic and oscillatory behavior of the switching model. At $\mathrm{t}=1 \mathrm{~ms}$, the input DC voltages are increased to $30 \mathrm{~V}$, hence the results show that the GSSAM is still capable of mimicking the converters' behavior even when the input DC source is reduced to be $20 \mathrm{~V}$ at $\mathrm{t}=2 \mathrm{~ms}$.

Buck-boost converters have a less effective coupling term compared to boost converter behavior. Therefore, the difference between the GSSAM of the buck-boost and the detailed model is very low even when the duty cycle is increased to be equal to 0.75 compared to the boost converter, as shown in Fig. 10. At $\mathrm{t}=0 \mathrm{~ms}$, the buck-boost converter begins to feed the DC load, and the inductor current and capacitor voltage increases gradually, due to the increasing duty cycle. Therefore, the transient response of the proposed model is identical to the switched model. At $\mathrm{t}=2 \mathrm{~ms}$, the requested power from the DC load reduces by half, and the proposed model is still capable to capture the transient response of the switched model. It can be clearly noted that the proposed GSSAM of the parallel buck converter presents the transient, steady state, and switching dynamic of the converters.

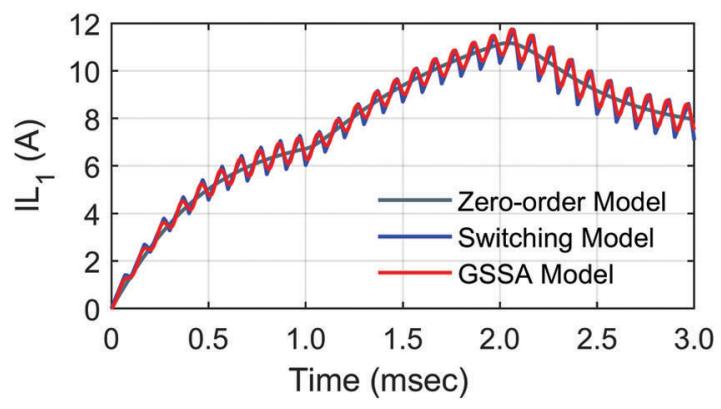

(a)

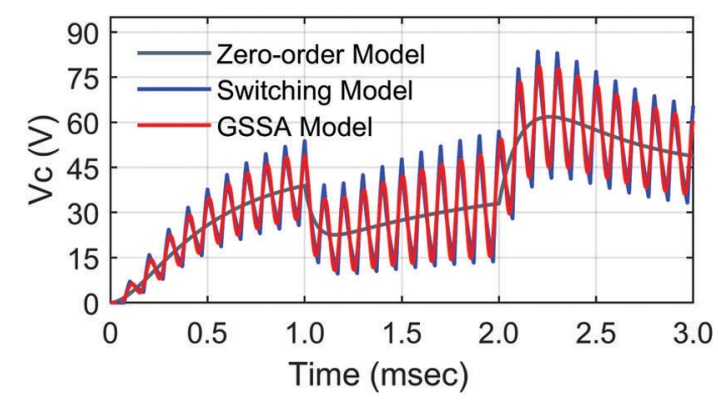

(c)

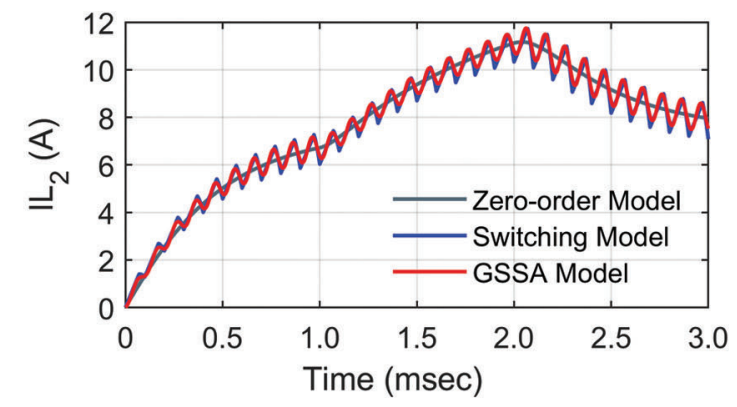

(b)

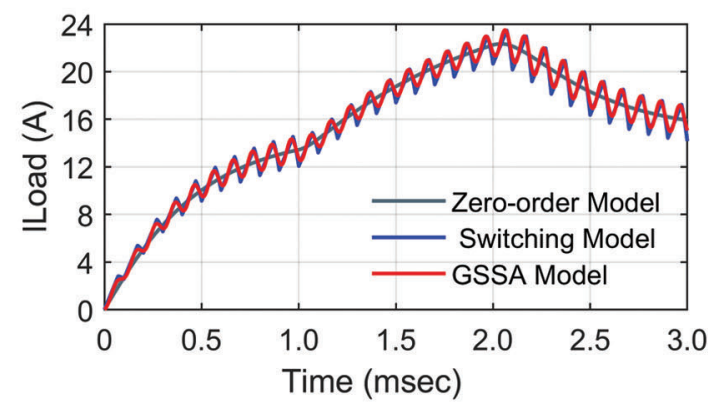

(d)

Figure 10: Parallel buck-boost converter currents and output voltage at $d=0.7$. (a) Converter $\# 1$ inductor current, (b) Converter \#2 inductor current, (c) Output voltage, (d) Load current

\section{Conclusion}

This paper proposes a generalized state-space averaging model of parallel DC-to-DC converters. The study draws a comprehensive comparison of a generalized state-space averaging model of parallel DC-toDC converters with a fully detailed switching model. Several advantages of the proposed generalized state-space averaging model can be achieved in order to design the controller loops and to conduct stability studies. This paper exposes some limitations of the generalized state-space averaging model of the DC-to-DC converter, especially for boost converter topology due to its complexity. The study in this paper compares the DC-to-DC converter's dynamic, oscillatory, and steady-state performance with a fully 
detailed converter switching model. A remedy for boost converter topology complexity can be achieved by considering more Fourier series harmonics-order of the switching function. The significant outcomes of this paper are confirmed via time-domain simulations while the test systems are simulated using a MATLAB/ SIMULINK environment.

Funding Statement: The author received no specific funding for this study.

Conflicts of Interest: The author declares that he has no conflicts of interest to report regarding the present study.

\section{References}

[1] D. Park and M. Zadeh, "Modeling and predictive control of shipboard hybrid DC power systems," IEEE Transactions on Transportation Electrification, vol. 7, no. 2, pp. 892-904, 2021.

[2] Q. Xu, N. Vafamand, L. Chen, T. Dragicevic, L. Xie et al., "Review on advanced control technologies for bidirectional DC/DC converters in dc microgrids," IEEE Journal of Emerging and Selected Topics in Power Electronics, vol. 9, no. 2, pp. 1205-1221, 2020.

[3] H. Moradisizkoohi, N. Elsayad and O. A. Mohammed, "A voltage-quadrupler interleaved bidirectional DC-DC converter with intrinsic equal current sharing characteristic for electric vehicles," IEEE Transactions on Industrial Electronics, vol. 68, no. 2, pp. 1803-1813, 2021.

[4] M. R. Habibi, H. R. Baghaee, T. Dragicevic and F. Blaabjerg, "False data injection cyber-attacks mitigation in parallel DC/DC converters based on artificial neural networks," IEEE Transactions on Circuits and Systems II: Express Briefs, vol. 68, no. 2, pp. 717-721, 2021.

[5] R. Mayer, M. B. El Kattel and S. V. G. Oliveira, "Multiphase interleaved bidirectional DC/DC converter with coupled inductor for electrified-vehicle applications," IEEE Transactions on Power Electronics, vol. 36, no. 3, pp. 2533-2547, 2021.

[6] P. S. Tomar, M. Srivastava and A. K. Verma, "An improved current-fed bidirectional DC-dC converter for reconfigurable split battery in EVs," IEEE Transactions on Industry Applications, vol. 56, no. 6, pp. 69576967, 2020.

[7] H. Alsiraji, "Cooperative power sharing control in multi-terminal VSC-HVDC," M.S. thesis, University of Waterloo, Canada, 2014.

[8] H. Alsiraji, "Operational control and analysis of a hybrid AC/DC microgrid," Ph.D. dissertation, University of Waterloo, Canada, 2018.

[9] H. Alsiraji and R. El-Shatshat, "Virtual synchronous machine/dual-droop controller for parallel interlinking converters in hybrid AC-DC microgrids," Arabian Journal for Science and Engineering, vol. 46, no. 2, pp. 983-1000, 2020.

[10] H. A. Alsiraji and R. El-Shatshat, "Serious operation issues and challenges related to multiple interlinking converters interfacing a hybrid AC/DC microgrid," in Proc. CCECE, Quebec, QC, Canada, pp. 1-5, 2018.

[11] K. Alshammari, H. A. Alsiraji, and R. El Shatshat, "Optimal power flow in multi-terminal HVDC systems," in Proc. EPEC, Toronto, ON, Canada, pp. 1-6, 2018.

[12] P. Azer and A. Emadi, "Generalized state space average model for multi-phase interleaved buck, boost and buckboost DC-DC converters: Transient, steady-state and switching dynamics," IEEE Access, vol. 8, no. x, pp. 77735-77745, 2020.

[13] T. Wu and Y. Chen, "Modeling PWM DC/DC converters out of basic converter units," IEEE Transactions on Power Electronics, vol. 13, no. 5, pp. 870-881, 1998.

[14] M. Salem, A. Jusoh, N. R. N. Idris and I. Alhamrouni, "Steady state and generalized state space averaging analysis of the series resonant converter," in Proc. CEAT, Sarawak, Malaysia, pp. 1-5, 2014.

[15] S. R. Sanders, J. M. Noworolski, X. Z. Liu and G. C. Verghese, "Generalized averaging method for power conversion circuits," IEEE Transactions on Power Electronics, vol. 6, no. 2, pp. 251-259, 1991. 
[16] V. A. Caliskan, G. C. Verghese and A. M. Stanković, "Multifrequency averaging of DC/DC converters," IEEE Transactions on Power Electronics, vol. 14, no. 1, pp. 124-133, 1999.

[17] S. R. Sanders, "On limit cycles and the describing function method in periodically switched circuits," IEEE Transactions on Circuits and Systems I: Fundamental Theory and Applications, vol. 40, no. 9, pp. 564-572, 1993.

[18] J. Mahdavi, A. Emaadi, M. D. Bellar and M. Ehsani, "Analysis of power electronic converters using the generalized state-space averaging approach," IEEE Transactions on Circuits and Systems I: Fundamental Theory and Applications, vol. 44, no. 8, pp. 767-770, 1997.

[19] A. Emadi, "Modeling of power electronic loads in AC distribution systems using the generalized state-space averaging method," IEEE Transactions on Industrial Electronics, vol. 51, no. 5, pp. 992-1000, 2004.

[20] H. Qin and J. W. Kimball, "Generalized average modeling of dual active bridge DC-DC converter," IEEE Transactions on Power Electronics, vol. 27, no. 4, pp. 2078-2084, 2012.

[21] J. A. Mueller and J. W. Kimball, "Modeling dual active bridge converters in DC distribution systems," IEEE Transactions on Power Electronics, vol. 34, no. 6, pp. 5867-5879, 2019.

[22] A. M. Stanković, S. R. Sanders and T. Aydin, "Dynamic phasors in modeling and analysis of unbalanced polyphase AC machines," IEEE Transactions on Energy Conversion, vol. 17, no. 1, pp. 107-113, 2002.

[23] L. Han, J. Wang and D. Howe, "State-space average modelling of 6- and 12-pulse diode rectifiers," in Proc. EPE, Aalborg, Denmark, pp. 1-10, 2007.

[24] Y. Xia, W. Wei, T. Long, F. Blaabjerg and P. Wang, "New analysis framework for transient stability evaluation of DC microgrids," IEEE Transactions on Smart Grid, vol. 11, no. 4, pp. 2794-2804, 2020.

[25] D. Li and C. N. M. Ho, "A module-based plug-n-play DC microgrid with fully decentralized control for IEEE empower a billion lives competition," IEEE Transactions on Power Electronics, vol. 36, no. 2, pp. 1764-1776, 2021.

[26] L. Xing, F. Guo, X. Liu, C. Wen, Y. Mishra et al., "Voltage restoration and adjustable current sharing for DC microgrid with time delay via distributed secondary control," IEEE Transactions on Sustainable Energy, vol.12, no. 2, pp. 1068-1077, 2021.

[27] M. A. Hassan and Y. He, "Constant power load stabilization in DC microgrid systems using passivity-based control with nonlinear disturbance observer," IEEE Access, vol. 8, no. x, pp. 92393-92406, 2020. 
CSSE, 2022, vol.41, no.2

Appendix A: System State Matrices

The system state matrix of n-parallel DC-to-DC converters are presented below, where $x_{a}$, and $x_{b}$ are defined in A.1:

$x_{a}=\frac{\sin (\pi d)}{2 \pi} ; \quad x_{b}=\frac{\sin ^{2}(\pi d)}{\pi}$

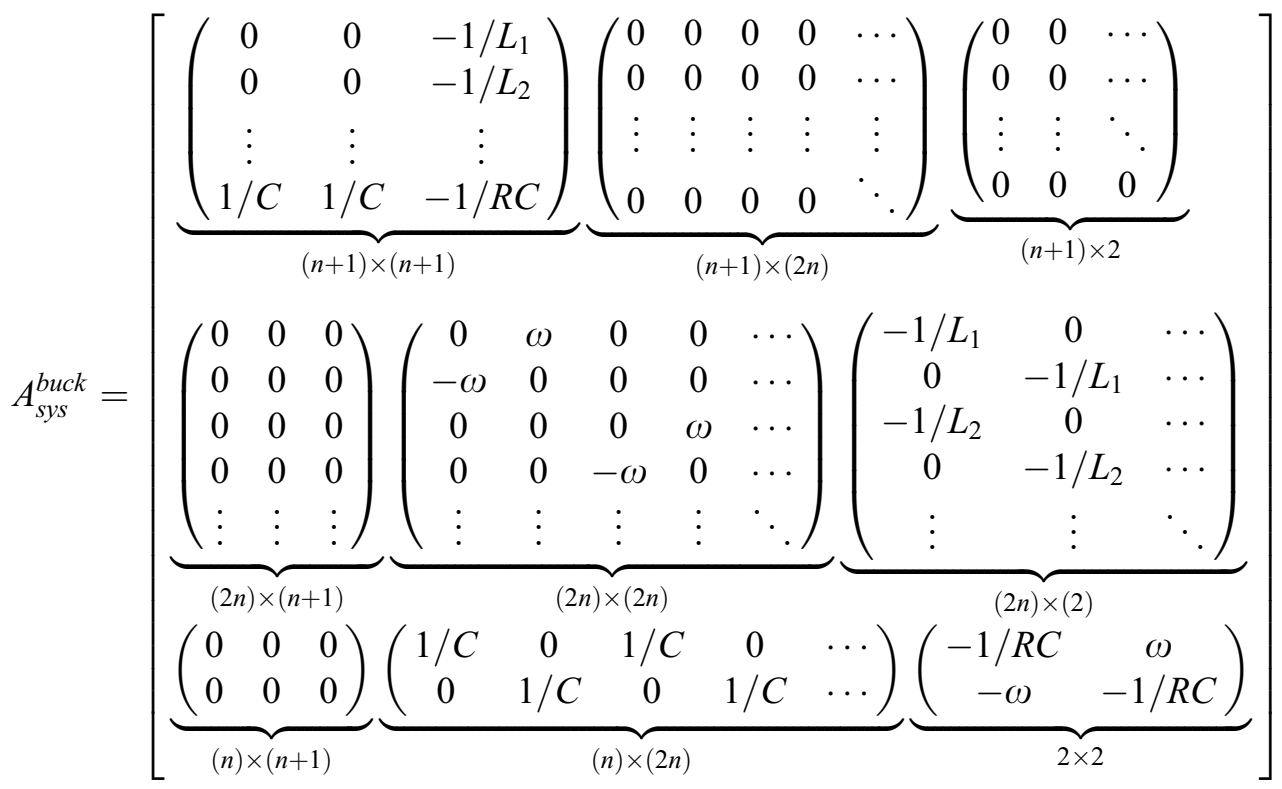

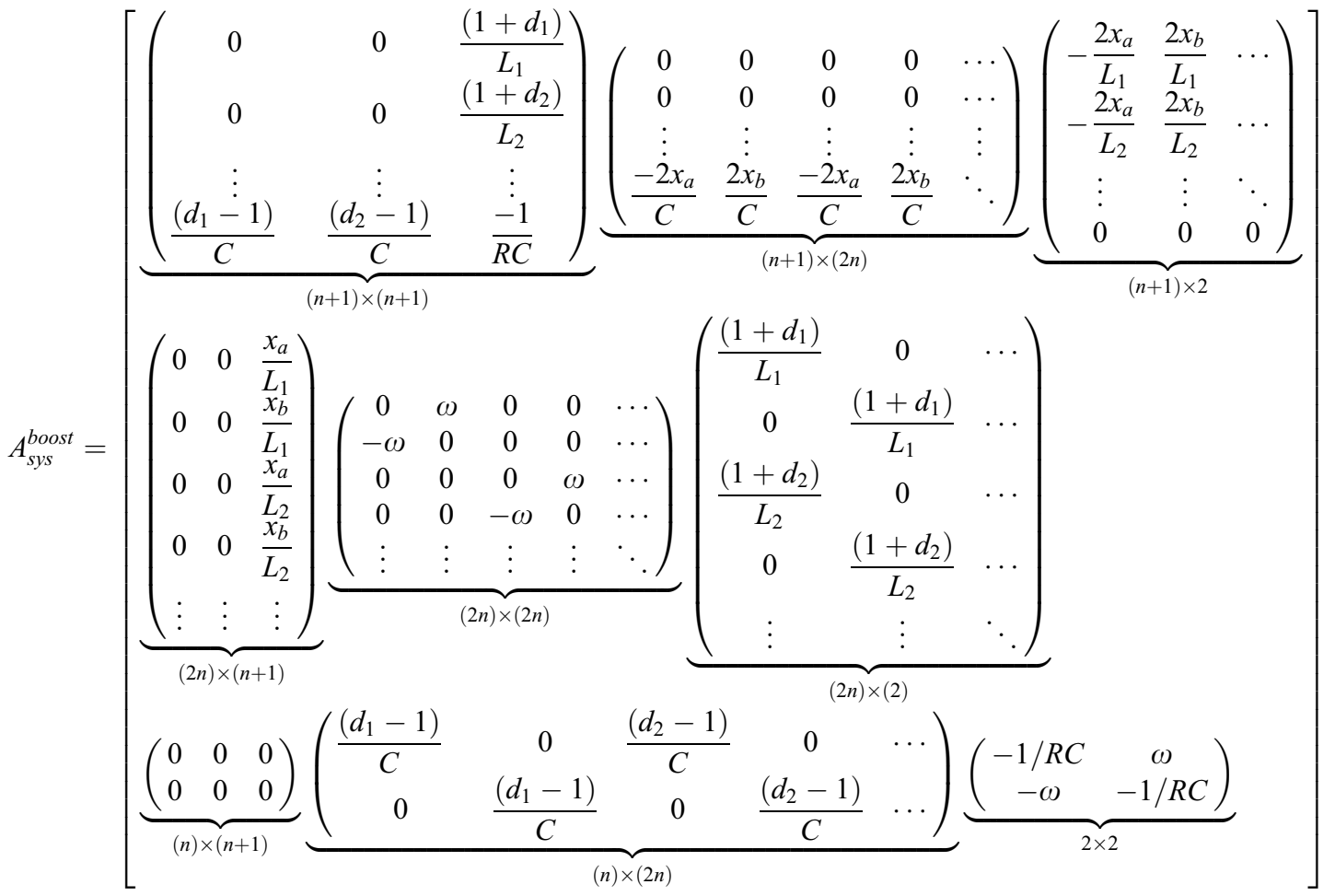




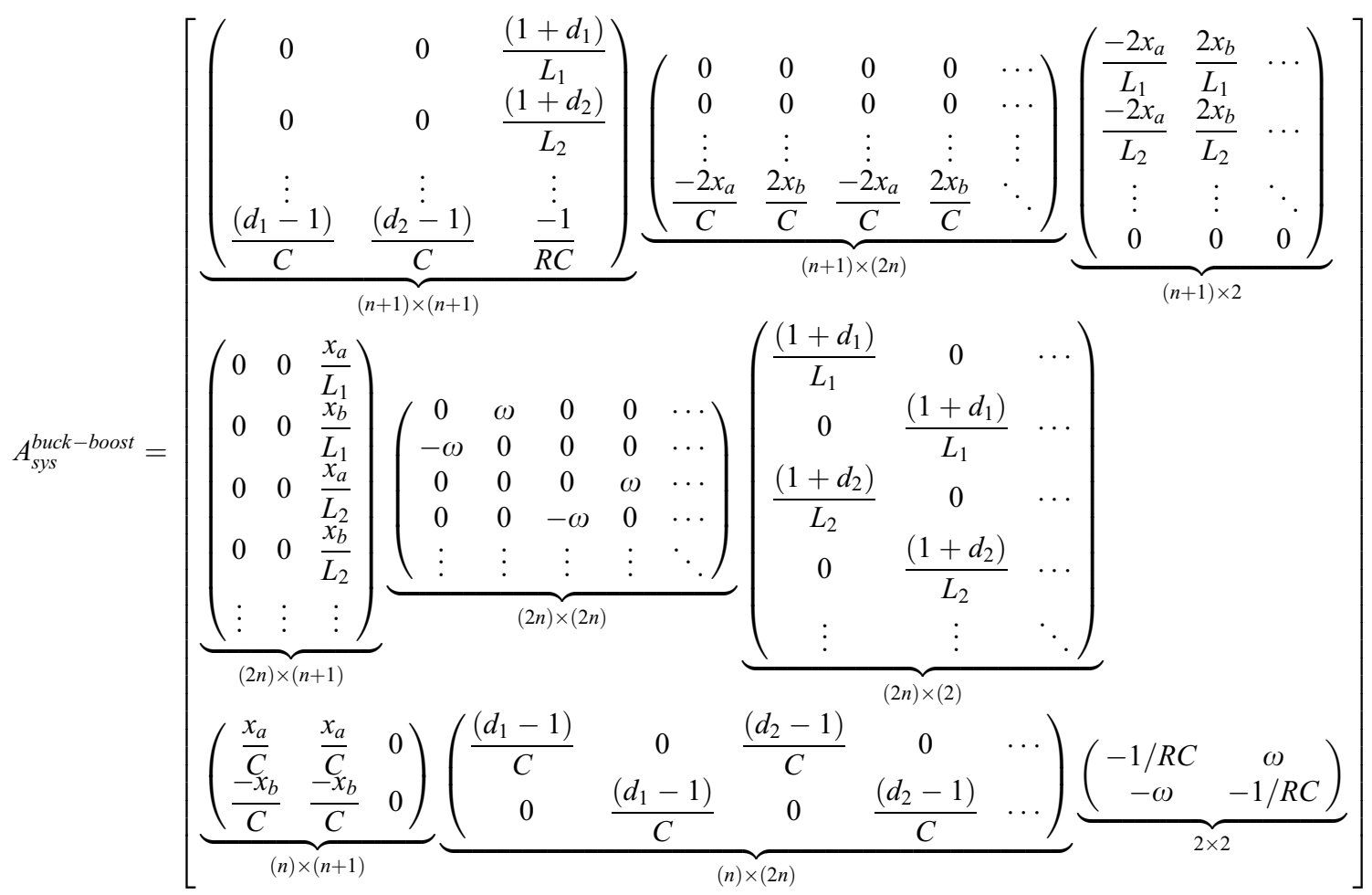

